\title{
THE USE OF SOCIAL MEDIA IN BANKS TO ENGENDER THE EMPOWERMENT OF WOMEN AND THEIR FINANCIAL INCLUSION IN ARAB COUNTRIES
}

\author{
Yusef Ali Yusef Yakubi ${ }^{1}$, B. Basuki ${ }^{2}$ and Rudi Purwono ${ }^{3}$ \\ ${ }^{1}$ University of Airlangga, Indonesia, yusef-ali-2018@feb.unair.ac.id \\ ${ }^{2}$ University of Airlangga, Indonesia, basuki@feb.unair.ac.id \\ ${ }^{3}$ University of Airlangga, Indonesia, rudipurwono@feb.unair.ac.id
}

\begin{abstract}
This study aims to classify and interpret the interacted communications between banks and users on social media and understand the role of these digital platforms to enhance the empowerment of women and their financial inclusion in banks in Arab countries. From five leading banks in five Arab countries, 100 users of the banks' social media site were selected; their interactive utterances were classified, analysed and interpreted. Content analysis tools were applied. The study reveals these key results: first, the use of social media in banks entails two-fold empowerment dimensions that are mutually beneficial for Users and Banks. Second, both flows of utterances from 'User to Banks' or 'Banks to Users' demonstrate that the highest ratios of the shared content are more closely associated with financial inclusion dimensions than aspects of users' empowerment. Third, women are found to be more socially and emotionally involved than men who show a relatively higher interest in banks' financial services and products. It was also determined that banks use social media to raise social and economic themes that support women in the region. However, the second and third results imply a gender gap in financial inclusion due to women still lagging behind. This study is different to others because it highlights the power of banks' social networks to trigger important gender and economic development themes in a highly conservative society; it also contributes to the literature by analysing and interpreting shared content from three extensive outlooks, which yield ample details and draw implications for banks' management and social media policy makers and regulators.
\end{abstract}

Keywords: Social media, Banks, Empowerment, Financial inclusion, Arab countries. JEL Classification: D63; G21; O16.

Article history:

Received : : September 14, 2019

Revised : December 6, 2019

Accepted : March 23, 2020

Available online : May 20, 2020

https://doi.org/10.21098/jimf.v6i2.1107 


\section{INTRODUCTION}

\subsection{Background}

Social networks and online communications have enabled users to interact with their institutions, communicate, express their desires or requirements, voice their concerns, share their experiences with others, exchange ideas, and perform financial transactions.

Many researchers from different parts of the world have examined the impact of social media in banks and have analysed online generated data to understand the influences and implications of shared content on social media pages. However, the focus of most of these studies has been mainly related to the banks and they seem to be concerned solely with marketing. Afolabi, Ezenwoke, and Ayo (2017) analysed social media data from five financial institutions in Nigeria, mainly to help banks identify competitive patterns and relationships derived from online data. Before that, Thoumrungroje (2014) empirically tested the impact of social media on 1,142 Thai consumers' trust in the 'electronic word of mouth' and their consumption of the advertised products. Even earlier, Mitic and Kapoulas (2012) examined the role of Web 2.0 and social media in Relationship Marketing (RM) in banking in the South East European region. In addition, Mucan and Özeltürkay (2014) studied 45 Turkish banks and discovered that banks used social media largely for marketing purposes. Sumathi and Sheela (2017) conducted an empirical study on the internet and social media content in State banks in India to improve the banking sector's opportunities by analysing users' feelings about banks' online services. Similarly, Sarkar and Saini (2018) applied sentiment analysis by extracted textual data from social media to probe customers' feedback related to peer-topeer (P2P) lending. Recently, Naeem (2019) analysed the level of users' utterances on the social media sites of Islamic Banks in Pakistan to test how this content might be used for modern marketing purposes. In Spain, Kaosiri et al. (2019) analysed sources of user-generated content (UGC) and investigated how these sources might influence tourist satisfaction.

Previous studies have almost exclusively focused on the impact of social media on banks, principally for marketing aims, as noted above. The implicational power of these digital platforms in financial institutions has not yet been utilised to bring empowerment, gender or development themes to the fore. Interactive shared content on social media has only previously been assessed to a very limited extent. Therefore, additional studies are needed to fully understand other possible dimensions and influences of utilising social media and online communications. This study attempts to contribute to filling this gap by highlighting the diverse empowerment elements and financial inclusion dimensions that accompany the use of social media in banks in Arab countries.

Generally, Arab countries rank relatively lower on gender equality than other societies and women are the most financially excluded group in the region. For this reasons, in this study, financial inclusion is linked with women's empowerment. Digital financial inclusion is described by the CGAP as 'digital access to, and the use of, formal financial services by the excluded and underserved population' (Ozili, 2018).

Women in Arab countries are constrained by several complicated multifactors that limit their movements and handicap their ambitions. Therefore, the 
existence of social networks in banks should allow them to interact with financial institutions using their digital devices. Batista et al. (2017) confirm that the internet enables individuals to connect and express themselves as never before, and this connectivity and access to information profoundly changes power structures and, potentially, society itself. This study tries to explore how users or customers, especially women, benefit from social media and how it helps them to feel more empowered. Customer empowerment, according to Peeroo, Samy and Jones (2018), is a 'process in which 'institutions and customers' systematically interact, learn, share information and integrate resources to jointly create value'.

It is necessary to gain a better understanding of how social media is used in banks and what types of empowerment and financial inclusion levels are reached in the Arab region. Specifically, the following research questions are addressed: 1. What sort of content do banks share with users on social media? 2. How does the use of social media in banks engender the empowerment of women and financial inclusion in Arab countries?

\subsection{Objectives}

This study aims to highlight the content shared on banks' social media platforms and, using social media and internet banking, gain an insight of the empowerment of women and their financial exclusion in Arab countries. It examines the use of social media from both sides of the service provider: the banks' perspectives and clients' views through online communications. The specific objectives are as follows:

1. To classify, analyse and interpret the shared content between users and banks on banks' social media pages.

2. To explore and identify the empowerment elements and financial inclusion dimensions that result from the use of social media in banks in Arab countries.

\section{LITERATURE REVIEW}

\subsection{Background Theory}

\subsubsection{The Empowerment Theory}

This study is based mainly on the 'Theory of Empowerment', which has received a lot of attention in modern literature and has been defined by many scholars. Zimmerman (2000) introduces some useful definitions that focus on the empowerment of individuals by viewing empowerment as a 'process where individuals learn to see a closer correspondence between their goals and a sense of how to achieve them, and a relationship between their efforts and life outcomes' Mechanic (1991). Another definition highlights the interactions within people's environments and marks out empowerment as 'an intentional, ongoing process centred in the local community, involving mutual respect, critical reflection, caring, and group participation, through which people lacking an equal share of valued resources gain greater access to and control over those resources' (Cornell Empowerment Group, 1989)'. One more definition, given by Rappaport (1984) explains that empowerment can take place at several levels and considers the 
process of empowerment as 'the mechanism by which people, organisations, and communities gain mastery over their lives'.

The empowerment construct will be utilised in this current study because it allows for exploring various empowerment dimensions that result from the use of social media at individual and organisational levels. Furthermore, the overall aim of this study seems to be in harmony with the conclusion of Zimmerman (2000) about empowerment as a process in which empowered people or organisations, such as social media users or banks, strive to gain control and participate with others to achieve goals and gain access to resources.

Applying the empowerment theory framework at individual and organisational levels of analysis means that empowerment is a continuing operation that leads to particular results through the incorporation of successive activities. At an individual analysis level, empowerment may refer to the desire and ability of individuals or customers, especially women, to use social media channels to express their needs and achieve their goals. At an organisational level, empowerment simultaneously represents banks' involvement and interactions with their customers to improve the effectiveness of banking services and their ability to achieve their goals and gain mastery over their markets.

There appears to be a link between the objectives of this study in identifying the implicational power and financial inclusion perspectives for individuals through the use of social media in a reactionary society, and empowerment research, which aims to recognise the capabilities and competences of individuals and consider the external surroundings that have direct influences on community problems. Furthermore, the empowerment theory apparently entails gender-development elements and incorporates both processes, which contain activities, actions, and outcomes for ultimate empowerment (Perkins \& Zimmerman, 1995).

Through the consideration of empowerment in this study, social media users are given opportunities through digital technology to accomplish their goals, driven by their desire to act and enjoy the end results. The use of social media can help them manipulate their skills to express their rights, convey their messages, and interact with banks. The use of social media also equips users with expressive and emotional rewards in addition to their ability to access banks for financial resources and, consequently, facilitate the solving of their problems and control over their lives.

\subsubsection{The Empowerment Model}

Amidst the different approaches to studying empowerment, this study focuses on the implicational power that comes from using social media in banks and makes use of the empowerment process model developed by Cattaneo and Chapman (2010) (see 3.2. Model Development).

The selected empowerment model uses the basis of the empowerment theory to show how social media can empower users (both male and female) and banks. It runs through six sequenced components that start from 'Goals' and move to 'Selfefficacy', 'Knowledge' and 'Competences'; these are required to achieve goals. In addition, 'Action' and 'Impact' are initiatives that are taken, resulting in the attainment of gains. The decomposition of empowerment into six components is 
necessary to understand the content of this study; this is because every component involves a particular capacity and displays an evolving level of empowerment for both users and banks.

To summarise, the central point of empowerment at an individual or organisational level is to seek growth and betterment through having motivations or goals and believing in one's abilities to perform actions and consequently acquire results or create impact, which becomes a measurement indicator or criterion of empowerment.

\subsubsection{Definitions of Social Media}

Torres, Augusto and Wallace (2018) refer to social media as an interdisciplinary and cross-functional concept that uses communication channels to create value for owners so they can achieve their goals. A Facebook page is defined by the Social Baker Database (2019) as 'a page you can create on Facebook for everything you find interesting or want to promote or represent whatever you want'.

According to Yakobi and Ngcamu (2016), the term social media has several definitions. It can be viewed as a means 'to engage with different forms of sociality on the Internet in the context of society' or as a system 'of discovery, distribution, consumption and conversation surrounding the media'. Other researchers define social media as a 'web-based tool for interaction that, in addition to conversation, allows users to share contents such as photos, videos, and links to resources'.

\subsubsection{Importance of the Use of Social Media in Banks}

Social media platforms allow users to interact with banks and with other users, express ideas and thoughts, share experiences, and exchange opinions that positively or negatively influence the image of banks and their reputation within communities. Kaletski and Randolph (2018) add that the promotion of rights among communities can lead to a country's growth and prosperity.

Alrwashdeh, Emeagwali and Aljuhmani (2019) conducted a study with more than 400 respondents; they stress that it is important for institutions and firms to focus on the development of online communication channels. Gandolfo (2019) points out that banks have recently started recognising the importance of social media as a new and powerful communication vehicle that could be exploited as a means for promoting the improvement and strengthening of customer relationships. However, there is still insufficient information and understanding about shared content on banks' social media platforms.

Social media dramatically influences communications channels by creating multi-content, styles and purposes that can be exchanged through interaction between organisations, individuals and communities. This is a huge challenge for companies and institutions that are still not fully aware of the benefits of social media in modern business and social life or how to deal with customers. 


\subsubsection{Purposes of the Use of Social Media in Banks}

Social media often utilises mobile and web-based technologies to create highly interactive platforms. Through these platforms, individuals and communities can share, discuss, and edit content created by users. Generally, as stated by Zimm (2019), access to technologies and their related services has become an important part of improving the living standards and welfare of people in modern world.

In the banking sector, the influence of social media has become more prominent for both financial institutions and users. Social media affects the way financial institutions communicate with the public, provide people with information, and talk about their products, services and offers. Financial inclusion and customer retention have become the apparent strategies of many banks and financial institutions in the region. This requires financial intuitions to deeply understand 'the typology of digital traffic on their networking platforms' to keep their market share and achieve their missions (Gandolfo, 2019).

Social media sites are used by customers as platforms for communication, networking, creating profiles, sharing experiences and discussing issues. Kietzmann, Hermkens, McCarthy and Silvestre (2011) argue that making use of social media facilities has become a phenomenon that requires an understanding of its functional building blocks; this is because it can have a significant impact on a company's image, sustainability and survival.

A study conducted by the American Bankers Association [ABA] (2017) asked 800 banks about their usage and management of social media; the study revealed that social media helped banks to become better known, friendly and reachable. According to their study, $76 \%$ of banks strongly agreed that social media was important and $90 \%$ favoured Facebook as their preferred social media platform.

In the Arab region, Al-Kandari et al. (2019) noticed that banks use Instagram for marketing, broadcasting information and supporting community engagement. An important part of their findings indicates that religious symbolism is reflected in the use of their social media platform by both the bank and the public. The bank here tends to benefit from the use of social media to address both religious and commercial objectives.

\subsection{Previous Studies}

The literature review indicates that social media platforms have become a crucial way for banks to interact with customers quickly, directly and effectively. Numerous studies have investigated the use of social media in banks, which have implemented various methodologies including content analysis.

In an early piece of research conducted by Allagui and Breslow (2016) called 'Social media for public relations: Lessons from four effective cases', the authors applied a collective case study technique to understand how social media could lead to the success of four award-winning campaigns that effectively used social media tools to promote public relations.

Another study, called 'An exploratory study on the impact of social media of selected commercial banks in the Eastern Cape Province, South Africa' was conducted by Yakobi and Ngcamu (2016); it aimed to study the impact of social media in commercial banks. It determined that social media positively contributed 
to effective communication within the banking industry. The study also affirmed that access to the internet and social media had become an integral part of people's daily lives.

Parusheva (2017) conducted a study entitled 'Social Media Banking Models: a Case Study of a Practical Implementation in Banking Sector', in which she emphasised the power of banks' social media usage over customer engagement growing a successful business. This study proposed four purposive social media usage models in banks 'as a marketing tool, as a communication channel, as a channel for feedback and reactions, and for transactional social banking'.

In the same year, Khan, Al-balushi, Algaithi and Al-shihi (2017) carried out a study entitled 'Impact of Social Media on Customers Satisfaction: Bank Muscat - A Case Study', to investigate the use of social media at Bank Muscat in Oman; the authors discovered that the utilisation of social media was very effective for both users and the bank. Users could communicate their suggestions, views and complaints while the bank was able to receive these communications and respond immediately.

Research was then conducted by Mahboub (2018) entitled 'The Impact of Social Media Usage on the Performance of the Banking Sector in the Middle East and North African Countries'; it aimed to study the impact of social media usage on the financial and non-financial performance of banks in twelve countries in the MENA. Another similar study was conducted by Al-Kandari et al. (2019) under the title of 'An Arab perspective on social media: How banks in Kuwait use Instagram for public relations'. Researchers employed the content analysis method to examine how banks in Kuwait were using Instagram to disseminate information and raise public relations.

Finally, a recent seminal work, entitled 'Content shared between banks and users on the social ecosystem: an inductive exploratory inquiry', was conducted by Gandolfo (2019); it contained a thorough analysis and interpretation of the interactive content between users and banks and banks and users in four financial institutions in Italy; the ultimate goal of the study was to understand the role of social media in the 'business models of credit institutions'.

Despite the significant contributions of previous work, most of their analysis was drawn from specific standard merchandised perspectives, largely at a country level. As observed, the use of social media to empower users, especially women, and to increase their financial inclusion appears to be unaddressed in the literature. The goal of this study is to fill these gaps.

Furthermore, this study considers the human touch by looking at utterances as a magnitude of human thoughts and feelings rather than artificially articulated words or superficially communicated posts. The study also aims to present a deep and comprehensive analysis of the shared content of these utterances from three perspectives: analytical, implicational and functional. 


\section{METHODOLOGY}

\subsection{Data}

\subsubsection{Sampling}

A sample of 100 users were selected from five leading banks in five Arab countries based on stratified sampling; the sample user selection was determined using the following criteria: the user appears on the bank's social media page as a user or prospective customer; the user produces a post or reacts to a published post on the bank's social media page; the user articulates intelligible and comprehendible utterance(s) either in English or in Arabic; the user expresses a comment, idea or opinion that has a meaning and a purpose.

A purposive sampling approach is employed in this study, which selects five out of the 13 banks classified by the Global Finance Magazine as the World's Best Banks in the Middle East. Most of these banks had been winners during the last two years and had received awards for their remarkable financial and social distinctiveness in the MENA region. See Table (1).

Table 1.

Sample of World's Best Banks in the Middle East

\begin{tabular}{lcc}
\hline Sr. & Bank & Country \\
\hline 1 & Commercial International Bank & Egypt \\
2 & Arab Bank & Jordan \\
3 & National Bank of Kuwait & Kuwait \\
4 & Bank of Palestine & Palestine \\
5 & First Abu Dhabi Bank & United Arab Emirates \\
\hline
\end{tabular}

Source: (Global Finance Magazine, 2018)

It is worth noting that the number of selected users and studied banks was determined to be sufficient to provide satisfactory answers to this study's two research questions, particularly following the reoccurrences of texts and utterances that had similar meaning or repeated themes during data collection and analysis. Therefore, this adequacy can be explained by not only the sample size, but also by the sufficient degree or acceptable level at which the research objectives were obviously met. The ample data might also be ascribed to other factors, such as the exploratory nature of this study and the type of analysis used.

As stated by Vasileiou, Barnett, Thorpe, and Young (2018), qualitative research experts believe that research sample size depends on various determinants; the existing literature shows that qualitative research tends to focus on the depth of exploration of the studied phenomenon, rather than its sample size. Sandelowski (1995) suggests that sample sizes should be 'large enough' to produce new and rich understanding of the phenomenon under study but 'small enough' to ensure that the depth of analysis is retained.

To that end, a sample selection of users and banks in this study involved a wide range of participants from various geographic locations and socioeconomic backgrounds. The purpose was to capture diverse communication elements, interactions, beliefs and opinions that could implicationally produce various 
categories and reveal several empowerment dimensions. Moreover, the selected five Arab countries contain both 'poor and rich countries'; this represents a diversified society with a population of more than $30 \%$ of the total world Arab population. However, due to the conservative nature of the selected studied group, the generalisability of the findings in this study seem limited to this specific location and community.

\subsubsection{Data Collection}

Data were collected from the service providers (banks) and customers (those who are identified as users through their interactions with banks using social media and the internet). The primary data, which contains utterances and posts from the banks were collected from the official Facebook pages of five banks from different Arab countries during the period 1/01/2019-31/05/2019.

Rieder (2013) argues that social media data are more advantageous than traditional sources and can be used to study various social problems and cultural events. These advantages include not only the cost, speed and depth of detail but also the rich contextualisation sustained by the close link between data and the technological quality of the communication channels they relate to.

For this study, Facebook is chosen because it is the most frequently used social media platform. Facebook provides useful space for firms and individuals to develop fruitful relationships (Gandolfo, 2019).

Table (2) indicates the number of participants by gender and the number of utterances for each bank.

Table 2.

Number of Participants by Gender and the Interacted Utterances Between Users and Banks

\begin{tabular}{lccccccc}
\hline \multirow{2}{*}{ Sr. } & Bank & \multicolumn{3}{c}{$\begin{array}{c}\text { Participants by } \\
\text { Gender }\end{array}$} & \multicolumn{2}{c}{ Interacted Utterances } \\
\cline { 2 - 8 } & & Total & Male & Female & Total & Users & Banks \\
\hline 1 & First Abu Dhabi Bank & 15 & 7 & 8 & 61 & 41 & 20 \\
2 & Arab Bank Jordan & 25 & 16 & 9 & 67 & 39 & 28 \\
3 & Commercial International Bank & 27 & 20 & 7 & 103 & 56 & 47 \\
4 & National Bank of Kuwait & 17 & 13 & 4 & 59 & 35 & 24 \\
5 & Bank of Palestine & 16 & 9 & 7 & 39 & 20 & 19 \\
\hline Total & & $\mathbf{1 0 0}$ & $\mathbf{6 5}$ & $\mathbf{3 5}$ & $\mathbf{3 2 9}$ & $\mathbf{1 9 1}$ & $\mathbf{1 3 8}$ \\
\hline
\end{tabular}

Sources: Social Media pages of the following banks: (AB-Jordan; BoP-Palestine; CIB Egypt; FAB United Arab Emirates, and NBK Group Kuwait, 2019).

\subsubsection{Data Analysis}

In relation to the content analysis of online texts, Hesse-Biber (2017) affirms that social media allows users to personalise their profiles and, through the writing of posts, create their own content. Other people can also reply to, comment on, and share this content. 
The unit of analysis in this study represents the communicated content that is directed from users to banks and vice versa on the banks' social media pages. Each piece of communicated content was considered as an utterance and was taken and classified based on its intended meaning and relevance. An individual utterance ranged from a text of multiple-words, phrases, or sentences to a single word.

After the data was collected from the banks' social media pages and their meaning was understood, the utterances were divided into a unit of meaning; each unit of meaning was coded based on their similarities and relevance. For example, utterances from users about receiving no response or delays from banks was coded under 'No answer to clients' calls, delays in answering, or rude treatment'. The related coded texts that contained certain themes and concepts were then classified into defined categories, for example 'Complaints' in the case described. The formulated codes of meaning units were grouped into categories and are exhibited in Tables 4 and 5.

The process of coding texts and phrases or words was repeated consistently so each one could be suitably labelled and placed under the right category linked to the research questions. The specified categories were formed as the core analysis in this study to initially answer the first research question about the type of content shared between users and their banks. These categories provided the scope for further analysis and the deeper interpretation of shared content to address the next research question and to show how the use of social media in banks could lead to women's empowerment and financial inclusion enhancement in Arab countries.

To that end, the classified categories with their component meaning units have been extensively analysed and interpreted from three broad views: analytical, implicational, and functional interpretations.

This study had gone through four general stages: the first two stages aimed to analyse and interpret the shared utterances while the last two stages were devoted to summarising and projecting the results. These four stages are exhibited in the following Figure (1).

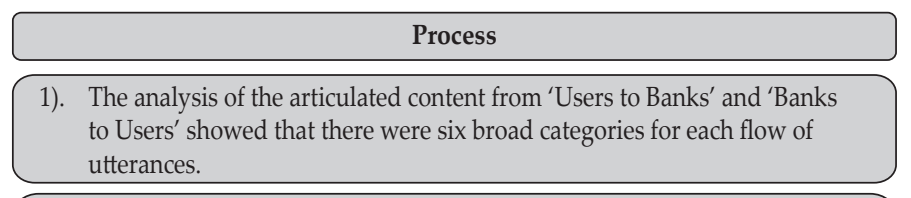

2). Interpreting and inferring the shared content that came from the two flows and the result was mutual empowerment elements (for Users \& Banks) and functional dimensions

3). Summarising the content analysis and interpretations that were done in the first and second stages and the result was the Main Model that presented twelve empowerment elements and financial inclusion dimensions for Users of social media.

4). Projecting Users' empowerment and financial inclusion dimensions by gender

Source: Developed by the authors

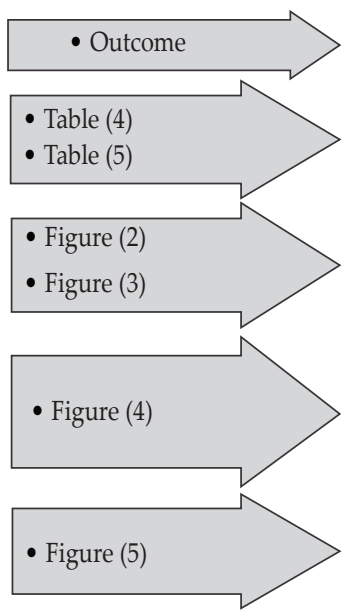

Figure 1.

Stages of Content Analysis, Interpretation and Result Presentation 


\subsection{Model Development}

This paper argues that the use of social media can cause diverse empowerment levels for both the banks and their users. To support the exemplification of the inferential and interpretational processes of the analysed shared content, this study used the model of empowerment process developed by Cattaneo and Chapman (2010). The model consists of six empowerment components as shown in Table (3).

Table 3.

Components of the Empowerment Process Model for Users and Banks

\begin{tabular}{|c|c|c|c|}
\hline Sr. & Component & Users & Banks \\
\hline 1 & $\begin{array}{l}\text { Personally } \\
\text { meaningful, } \\
\text { power-orientated } \\
\text { goals }\end{array}$ & $\begin{array}{l}\text { Users seek to: } \\
\text { 1. complain } \\
\text { 2. request information } \\
\text { 3. suggest ideas } \\
\text { 4. admire and congratulate } \\
\text { 5. criticise } \\
\text { 6. express other content }\end{array}$ & $\begin{array}{l}\text { Banks seek to: } \\
\text { 1. promote and advertise } \\
\text { 2. notify } \\
\text { 3. offer training and jobs } \\
\text { 4. spread awareness } \\
\text { 5. reply and explain } \\
\text { 6. greet and wish }\end{array}$ \\
\hline 2 & Self-efficacy & $\begin{array}{l}\text { Users have the interest and belief that } \\
\text { they can reach their goals. }\end{array}$ & $\begin{array}{l}\text { Banks have mechanisms and } \\
\text { resources in place to learn about } \\
\text { customers or users' interests and } \\
\text { beliefs and reach their goals. }\end{array}$ \\
\hline 3 & Knowledge & $\begin{array}{l}\text { Users know about banks' social media } \\
\text { tools and what can be posted. }\end{array}$ & $\begin{array}{l}\text { Banks know about the interacted } \\
\text { content and the communicated } \\
\text { language. }\end{array}$ \\
\hline 4 & Competence & $\begin{array}{l}\text { Users use their writing and expression } \\
\text { skills to approach their goals. }\end{array}$ & $\begin{array}{l}\text { Banks own the facilities and online } \\
\text { techniques required to achieve their } \\
\text { goals. }\end{array}$ \\
\hline 5 & Action & $\begin{array}{l}\text { Users take action through participation } \\
\text { and involvement. }\end{array}$ & $\begin{array}{l}\text { Banks assess the financial and non- } \\
\text { financial gains of taking action then } \\
\text { act and react accordingly. }\end{array}$ \\
\hline 6 & Impact & $\begin{array}{l}\text { Users obtain participation and social } \\
\text { media outcomes pertaining to their } \\
\text { goals. } \\
\text { This also influences how they move } \\
\text { forward to repeat other components of } \\
\text { the empowerment process. }\end{array}$ & $\begin{array}{l}\text { Banks obtain the effects or results } \\
\text { after reaching their goals. } \\
\text { Banks also encourage customers to } \\
\text { take action and interact frequently. }\end{array}$ \\
\hline
\end{tabular}

Source: Adapted from Cattaneo and Chapman (2010)

Due to its applicability and flexibility, the above empowerment model seems convenient for this study. The model was principally based on earlier theories of empowerment and past studies that show empowerment as a repetitive process, which specifies the essential elements and sets up an appropriate approach to studying the empowerment notion.

It must be noted that this theoretical empowerment background adds some explanatory insights to the content analysis and inferential and interpretational processes, which eventually lead to the development of this study's main model (Figure 4), which is shown in the results section 4.1.2. 


\subsection{Method}

The content analysis technique is adopted in this study. Hesse-Biber (2017) illustrates that content analysis tackles the identification of 'a text or group of texts and closely study them to better understand the characteristics of what is included and not included in the textual object of analysis'.

Textual and content analysis aims to identify the dimensions and mainstream concepts of empowerment within a text and provide insights into how comments and posts might be influenced by the commonly occurring patterns of meaning.

Afolabi et al. (2017) carried out a competitive analysis of social media data in banks and discovered that social media text analysis provides important competitive advantage trends; this is also a useful source of information for banks' management.

This study used utterances taken directly from the social media pages of banks' websites; they were analysed and interpreted and did not rely on any kind of software. Gandolfo (2019) states that full automated research software cannot confirmatively recognise exact linguistic and contextual 'nuances'.

The research also utilises qualitative data, which seems to be advantageous to this study due to the high level of rich data available within online communities. The data especially helped to deeply understand the impact of social media and the internet on the social and influential empowerment of users as well as financial inclusion in banks in the Arab world. Large quantitative elements are also included in the analysis and findings projections.

\section{RESULTS AND ANALYSIS}

\subsection{Results}

Through this study, 329 individual content elements were collected from 100 participants, who used the official Facebook social media pages of the five studied banks for different types of interactions. From these 329 total posts, 191 were generated by users and 138 were reactions from the banks. Moreover, the content of all the relevant advertisements and published notes that were posted by banks during this study were also considered in the analysis and interpretations.

\subsubsection{Type of Interacted Communications Between Banks and Users}

The analysed content in this study was derived from two streams of data. The first were the utterances of users or customers to banks and the second were utterances or responses that were sent from and/or shared by banks to their users; these utterances were analysed to obtain and understanding of the essence of the textual content between banks and their users.

Tables (4) and (5) present the classification of the collected data into six main categories of each coded flow based on their conceptual meanings and relevance. Later, the coded categories were further analysed and interpreted. 


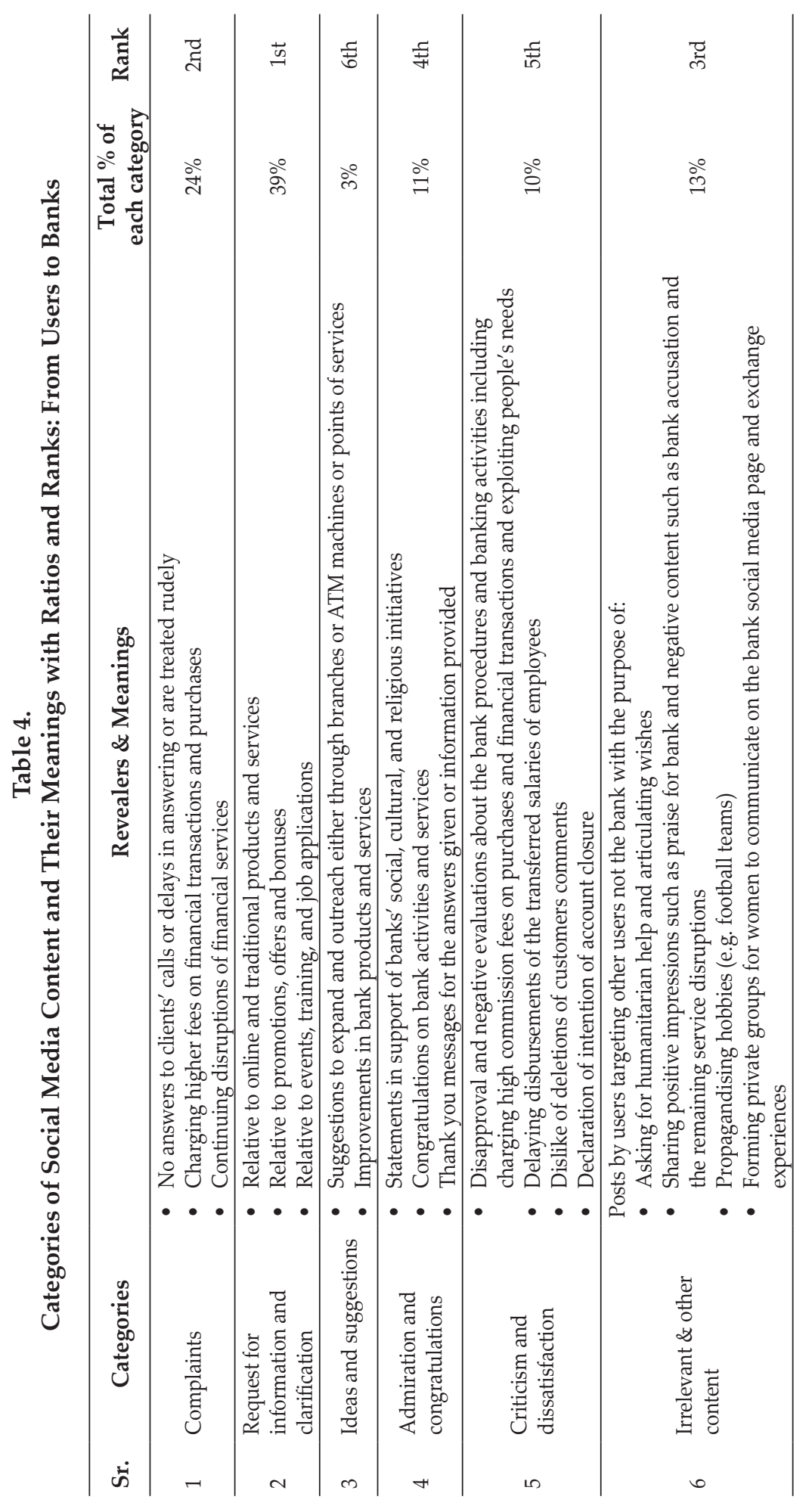




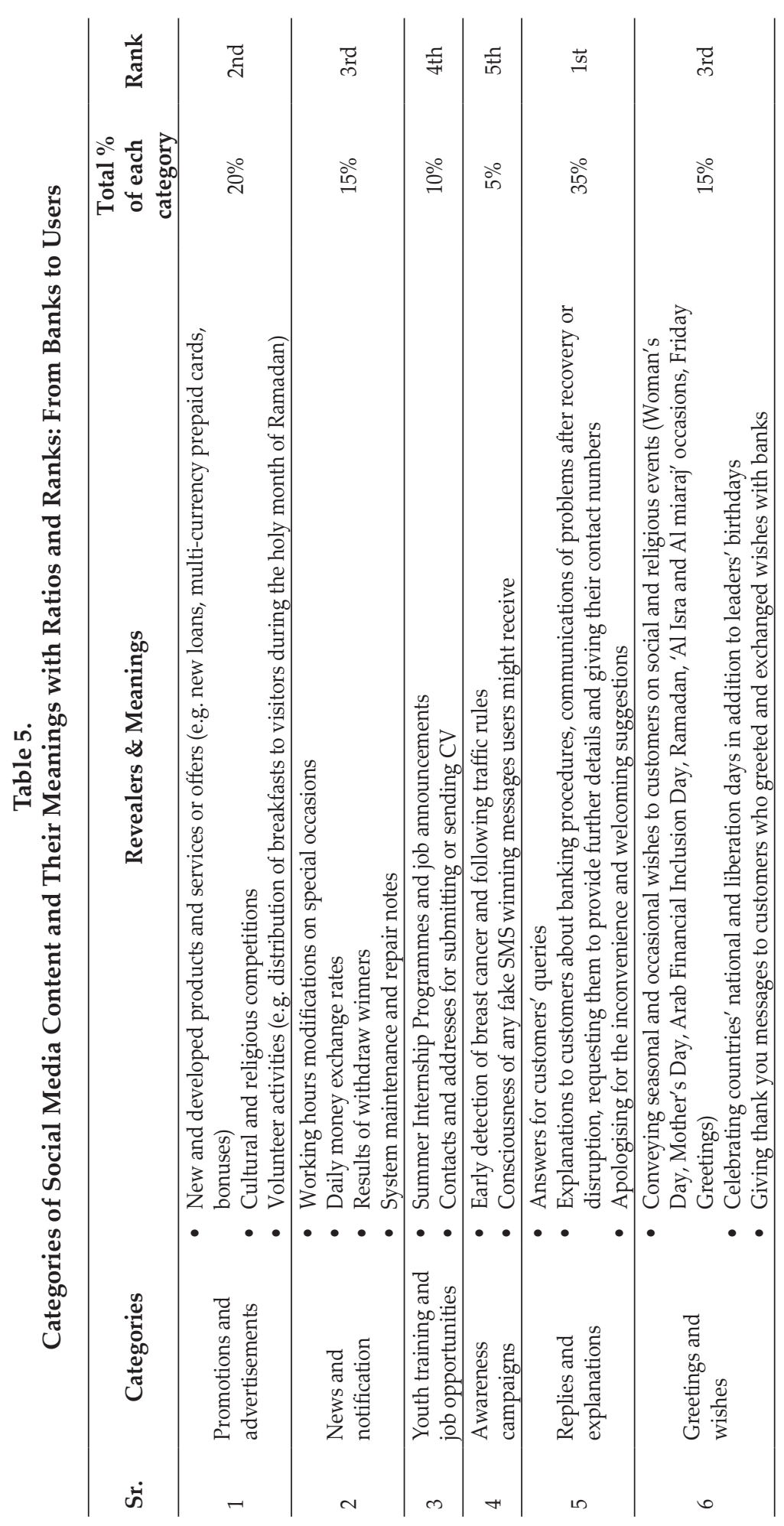




\subsubsection{Empowerment Elements and Financial Inclusion Enhancement}

Users of banks' social media pages in Arab countries were found to be empowered by the internet and modern technologies in relation to interactive social networking and financial concerns. During the content analysis, it was perceived that both male and female users were notably able to interact with banks and other users and freely express their needs, wants, queries, opinions, beliefs, criticisms and feelings.

The empowerment connotations were reflected in users' utterances; at the same time, these empowerment dimensions were reciprocally contingent on banks' reactions. This was also noted in most of the banks' replies and interactions.

Figures (2) and (3) manifest the two-fold empowerment and functional dimensions of each social media category regarding the utterances from both users to banks and banks to users.

Please note that the construction of Figures 2 and 3 was based on the content analysis, interpretations, and inferences of the utterances in each category. For example, the dual empowerment dimensions in Figure (2) for Category 1 (complaints) was set as 'Rightful vs Corrigible'. This category 'Rightful' referred to the users because they had an established complaint or claim; 'Corrigible' referred to banks because banks received the complaint and admitted the need for correction.

Dual empowerment dimensions can also be seen in Figure (3), for example, for Category 1 (promotions and advertisements) was set as 'Stimulative vs Satisfied'. This category 'Stimulative' referred to the banks because they stimulated users or customers with their products and service awareness; 'Satisfied' referred to users because they were given more options regarding which products or services would best suit their needs. 


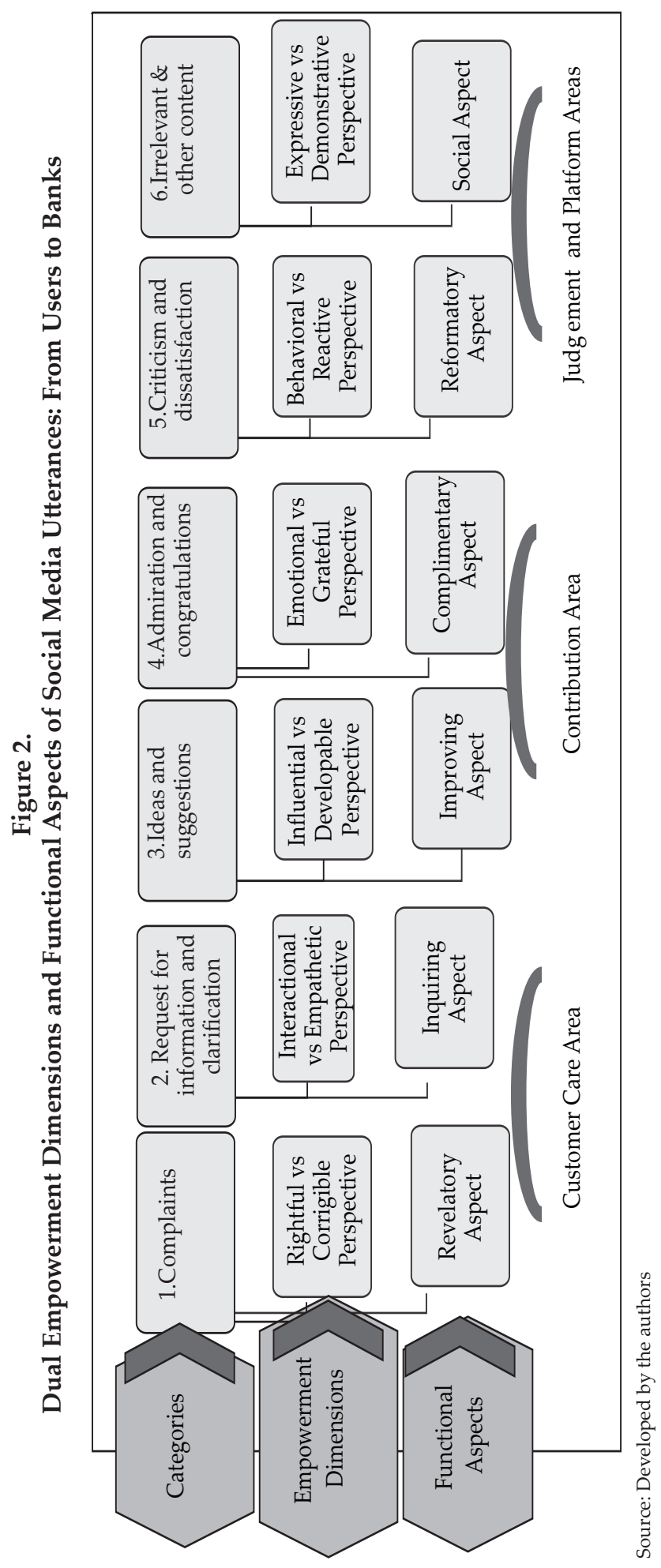




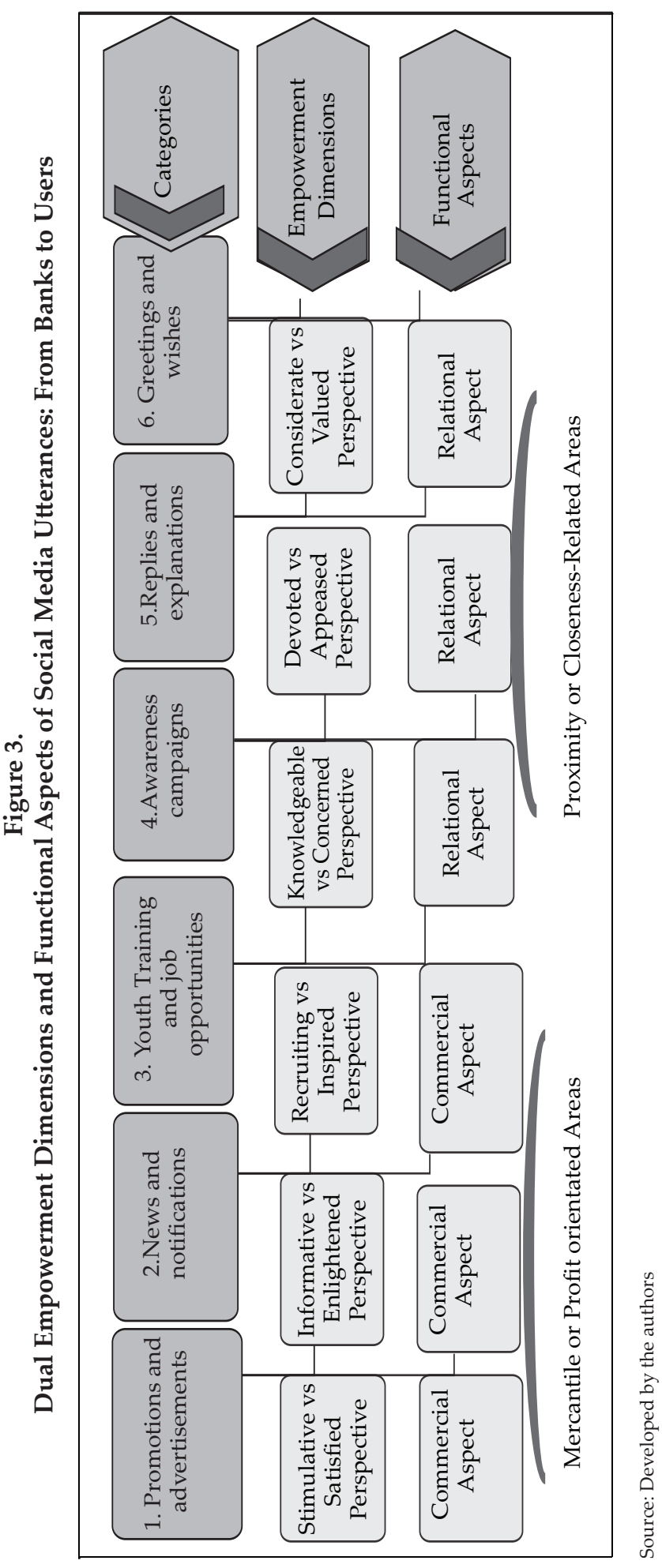


Figures (2) and (3) show that all empowerment dimensions for users were interdependently opposed to the banks' responses. The interpretations of the shared utterances on banks' social media pages proved that the dual-dimensional facets of empowerment mutually benefited both users and banks.

It should be mentioned that banks used their social media pages to raise important and meaningful social and economic themes for users, particularly women. Women's Day (on 8th March), Mother's Day (on 21st March) and Arab Financial Inclusion Day (on 27th April) were all featured in an appealing manner on the banks' social media pages. The date 27th April marked a particularly important event for triggering financial inclusion in the region; it was initially adopted by the Arab Monetary Fund [AMF] (2018) as an appropriate occasion to consolidate financial inclusion principles in financial institutions across all Arab countries.

Regarding empowerment and financial inclusion dimensions, the following model in Figure (4) displays an exhaustive synopsis of the outcomes of users' empowerment and financial inclusion enhancement, providing ratios for the content of each category. It should be emphasised that Figure (4) summarises and casts the twelve empowerment and financial inclusion dimensions that were interpreted and inferred from the two flows of utterances; nevertheless, these twelve dimensions reflect only users' perspectives, which is the overall aim of this study.

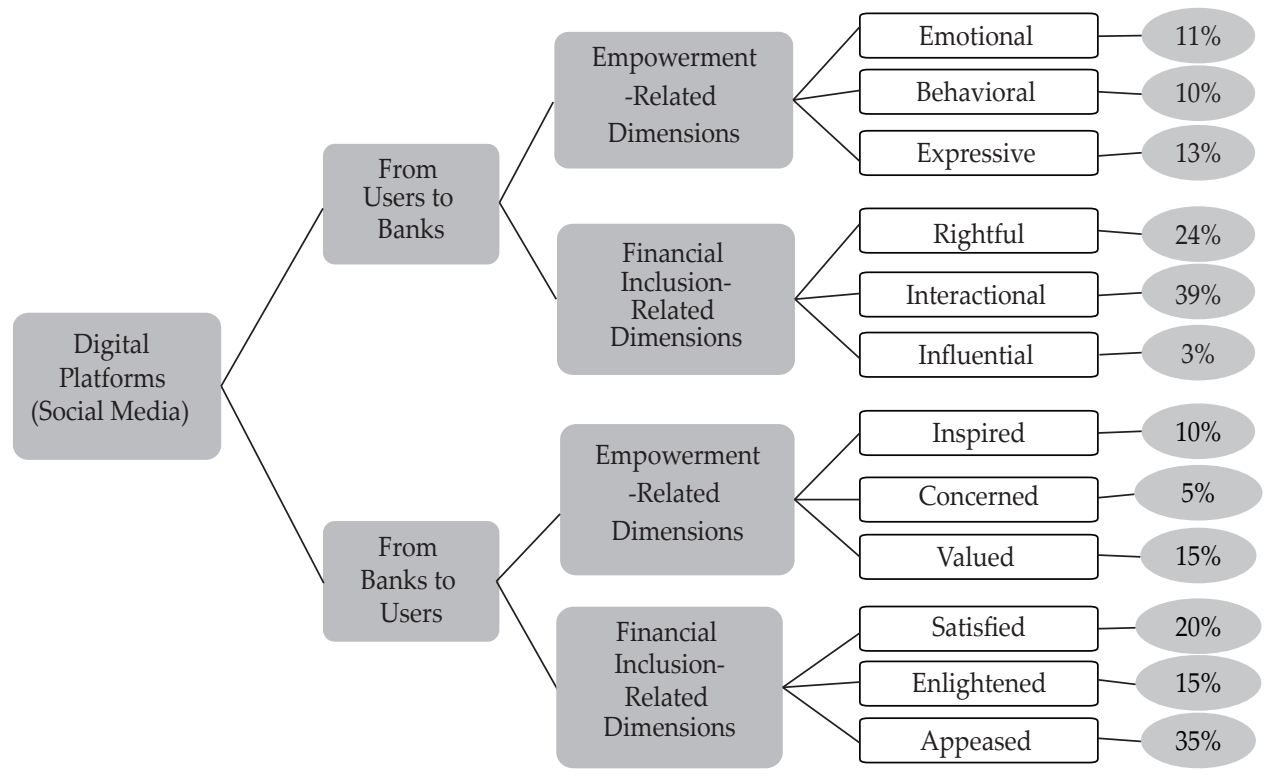

Source: Developed by authors

Figure 4 .

Model of Users' Empowerment and Financial Inclusion Dimensions 
The model in Figure (4) shows that social media users empowerment and financial inclusion-related dimensions, with a proportion of the shared content on each side.

The flows of utterances from either 'User to Banks' or 'Banks to Users' demonstrate that the highest ratios of the shared content are more closely associated with financial inclusion-related dimensions than aspects of users' empowerment. For instance, the utterances from 'Users to Banks' contain 39\% of the communication, which is obviously linked to financial inclusion under the 'Interactional dimension, in which users can interact with banks to request information and clarification about offers and other financial service issues. The next dimension 'Rightful', makes up $24 \%$ of the shared content and exemplifies the practice of users' basic rights to complain about poor services or customer inattention; this is also related to financial inclusion-related dimensions.

Similarly, utterances from 'Banks to Users' encompass the highest ratio of $35 \%$ of the shared content under the empowerment dimension 'Appeased', for which users are typically pacified by banks' responses and clarifications on financial matters; this is also affiliated with financial inclusion-related dimensions.

Other empowerment dimensions directed solely to users empowerment come from the 'Users to Banks' flow , include 'Expressive' with 13\%, 'Emotional' $11 \%$ and 'Behavioural' $10 \%$ where users are able to communicate, show their admirations as well as dissatisfactions.

The stream of utterances from 'Banks to Users' reflect users' empowerment dimensions and 'Valued' accounts for 15\%, which relates to users' feelings and values, 'Inspired' accounts for 10\% through internship programmes and employment skills, and 'Concerned' accounts for 5\%, which relates to users being exposed to necessary awareness campaigns.

This model affirms the important role of social media in banks by enhancing financial inclusion to the empowerment of both male and female users. Through social media, users can interact, complain, express their feelings and emotions, and influence others. At the same time, the use of social media seems to allow users to feel inspired, concerned, valued, satisfied, enlightened, and appeased.

Finally, it should be noted that all of the empowerment and financial inclusionrelated dimensions exhibited in the model in Figure (4) principally specify social media users, irrespective of their gender. Figure (5) in the next section will illustrate empowerment in relation to gender classification.

As well as exploring the type of shared content and its revealed implications, this study also intended to examine the actual findings to determine whether the use of social media could support women's empowerment and financial inclusion in the banking sector in Arab countries. Figure (5) shows the ratios of empowerment by gender for each category of the shared interacted communication from users to banks. 


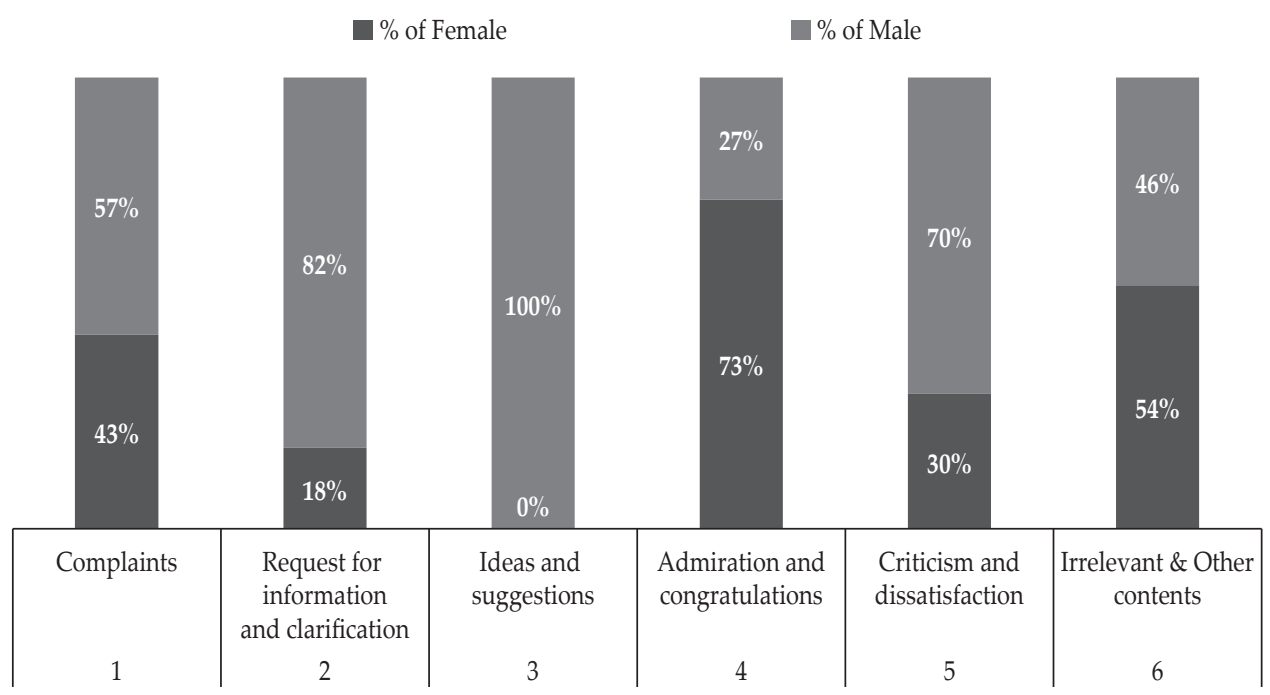

Figure 5.

Ratio of Participants by Gender for each Category

Figure (5) indicates that female users were more emotionally and expressively empowered; this is because $73 \%$ of them seemed to prefer to make pleasing comments, demonstrate their appreciation, and express their thankfulness under Category 4 (Admiration and congratulations) and $54 \%$ of them communicated with other female users and shared their experiences on banks' social media pages. Women were not interested in proposing suggestions for the betterment of banking, but in accordance with male users, they accounted for $43 \%$ under Category 1 (Complaints) to convey their demands and to obtain better financial services and care.

Male users, however, were more inclined to influence and make suggestions under Category 3 (Ideas and suggestions). Remarkably, 82\% of male users in Category 2 (Request for information and clarification) tended to interact with banks and delve into financial services and banking issues at a far higher rate than female users, who accounted for only $18 \%$ of the same category. Similarly, for Category 5 (Criticism and dissatisfactions) male users tended to be more evaluative and were behaviourally empowered with $70 \%$ more prominence than female users, who accounted for only $30 \%$.

Therefore, it can be concluded that the use of social media in banks in Arab countries is an effective, yet diverse, digital method of empowering both male and female customers and financial inclusion.

Female users or customers conspicuously use these digital channels mainly to express their feelings and social interests rather than for obtaining information about banking and financial products or services. Men used the social media pages more often than women to interact with banks about issues related to financial products and services. 
It should be recalled that gender empowerment is an important field that has emerged in different feminist, cultural and psychological studies. This study highlights a gender empowerment theme through the use of banks' social media pages and, more importantly, its findings are consistent with various empirical evidence and existing empowerment theories. One of these theories is reflected in the work of Kwauk and Braga (2017), who specify that women possess empowerment competences, which can be developed through the empowerment 'Knowledge, Skills, and Attitudes (KSA)' approach. When relating this theory to the outcomes of this study, social media users appear to have KSA competencies because they understand banks' social media tools, what to post, and what is posted. Users seem to be skilful in express themselves and behaving the right way; they use their attitudes and manners to convey their feelings and needs and to attain their ultimate empowerment ambitions.

Further evidence can be seen in an empirical study conducted by Shin, Perdue and Pandelaere (2019) about the effect of tourists' 'knowledge value co-creation process' on empowerment; researchers discovered that hotel customers were more empowered when they were given personal and individual attention and they consequently benefitted from positive experiences. These findings seemed similar to that of banks' social media users, who were also empowered by the personal care and treatment they got from banks' responses to their queries, complaints and greetings. Banks also showed them respect on these social media pages.

Interestingly, Singh et al. (2019) conducted a significant empirical study based on theories of gender empowerment and proved that, through bank account ownership, there is a link between financial inclusion and health-related benefits through women's knowledge about the value of healthcare issues, particularly the use of reproductive and maternal health services in India. Their study revealed that women with bank accounts, who were implicitly financially included, were using reproductive and maternal health services and visiting health centres more frequently than those women who did not own bank accounts. In the same way, users of social media in banks, who were also implicitly financially included, were empowered by associated benefits including health-related utilities such as breast cancer early detection; this occurred via banks' awareness campaigns and other empowerment elements.

\subsection{Analysis and Interpretations}

The content of the shared utterances from 'Users to Banks' and vice versa was analysed and interpreted from three perspectives: first, analytically to show semantic themes; second, implicationally to derive empowerment components; and third, functionally to display operational and strategic principles.

\subsubsection{First: Analytical Interpretation}

\subsubsection{The Articulated Utterances from Users to Banks}

As demonstrated in Table (4), among the social media total content items, Category 2 (Request for Information and Clarification) made up 39\% of the total percentage, 
with no other category approaching this figure. The next largest percentage went to Category 1 (Complaints) with $24 \%$ of the total.

Category 6 (Irrelevant and Other Content) is worth noting because it comprised the third highest percentage and constituted approximately $13 \%$ of the shared posts. This category contained communications brought forth by users but targeted other users and not the bank for various reasons, including expressing wishes, hobbies, asking for humanitarian help, and sharing impressions, e.g. positive words of commendation for banks or negative accusations relating to service disruptions. Here, it was also noticeable that some female users established private groups on banks' official social media pages and invited only women to join and communicate within the group.

Category 5 (Criticism and Dissatisfaction) contained disapproving remarks and feelings of discontent, accounting for $10 \%$ of the total users' shared content.

Category 3 (Ideas and suggestions) accounted for a minimal 3\%; this related to customers' significant contributions to banks' social media pages with unasked ideas and suggestions, which called for ways to improve and expand banking services.

Category 4 (Admiration and Congratulations) ranked fourth with approximately $11 \%$ of the total categories. Most content in this category covered customers' approval and delight for the banks' religious, cultural, and social activities.

\subsubsection{Articulated Utterances from Banks to Users}

Table (5) shows that most content shared by banks for users was included in Categories 5 and 1, which both constituted more than half of the total content. Category 5 (Replies and Explanations) attained the highest portion of about $35 \%$ and was related to answering users' questions about problems they faced and explaining relevant banking procedures and financial services such as the requirements for opening bank accounts, applying for loans, and savings. Category 1 (Promotions and Advertisements) formed about $20 \%$ and was pertinent to banks' products, services and offers. The category also addressed some of the banks' religious and cultural events.

Categories 2 (News and Notifications) and 6 (Greetings and Wishes) both ranked $3^{\text {rd }}$, with a similar proportion of about $15 \%$ of the banks' entire communications. Category 2 was more associated with the declaration of amendments in the banks' working hours, its achievements, events, or campaigns, the periodic prize draw winner's disclosure, and other online notices. However, Category 6 involved public greetings in relation to several national, social, and religious occasions such as celebrating the country's liberation day, women's day, and financial inclusion days etc. During these celebration periods, banks made several offers and bonuses that appeared to be supportive of women in particular.

Category 3 (Youth Training and Job Opportunities) accented for about 10\% in relation to internships or apprenticeships exposed to people, especially youths, as well as announcements of bank job vacancies.

Finally, the smallest ratio of content, which account for around 5\%, was within Category 4 (Awareness Campaigns); this category contained advice about the 
importance of early breast cancer detection and other campaigns, which urged customers to follow traffic rules and so on.

\subsubsection{Second: Implicational Interpretations}

\subsubsection{The Articulated Utterances from Users to Banks}

In terms of dual empowerment, as exhibited in Figure (2), Category 1 (Complaints) represents equality and basic human rights, which made users avail expressive channels. These needed to be addressed by banks as soon as possible. Therefore, the empowerment perspective here was 'Rightful vs Corrigible'.

Category 2 (Request for Information and Clarification) comprised interactive messages that required empathy and consideration from banks, including responding to users' inquiries, removing obstacles, eliminating ambiguity or confusion, and ensuring proper service utilisation. Therefore, the perspective here was 'Interactional vs Empathetic'.

In Category 6 (Irrelevant and Other Content), users utilised banks' social media pages to share ideas and create content that was share-worthy for others. Some users provided information and asked for help from other people, while other users formed private groups to communicate and exchange experiences. These were visible on banks' social media. This perspective was labelled 'Expressive vs Demonstrative'.

Category 4 (Admiration and Congratulations) enabled users to feel thankful and respond to posts on special events which made them undergo more positive emotions, enjoy good experiences, and build strong relationships. Therefore, it was labelled as the 'Emotional vs Grateful' perspective.

For Category 5 (Criticism and Dissatisfaction) the empowerment perspective was felt through the appraisal and practice of freedom of speech on the banks' social media pages; this proved fundamental power, especially for women in the region, and this feeling typically rendered crucial insights for change. It also helped users to see how banks responded to their views and the extent to which they were really heard. This was seen as a 'Behavioural vs Reactive' perspective.

Finally, the content of Category 3 (Ideas and Suggestions) implied that users were able to shape important decisions while empowering others (banks) to act. So, this was seen as the 'Influential vs Developable' perspective.

\subsubsection{The Articulated Utterances from Banks to Users}

As illustrated in Figure (3), regarding utterances from banks to users, the content of Category 1 (Promotions and Advertisements) helped banks in different ways to increase their product and services awareness, stimulate customer traffic, and enrich their social experiences by obtaining preferred products and services and, thus, raise their content. This was labelled the 'Stimulative vs Satisfied' perspective.

Through Category 2 (News and Notifications), customers were updated with daily money exchange rates, the arrival of transferred salaries for non-banked employees, any evolving events that increased engagement, or other important alerts that required immediate attention. It was observed that banks chose several social media tools to update and engage customers, for example, using videos, 
pictures, messages and links to ensure that users are effectively informed; users could leave direct comments and reactions than they would with other less direct methods, e.g. emails or other conventional communication channels. This was labelled as the 'Informative vs Enlightened' perspective.

The content of Category 3 (Youth Training and Job Opportunities) indicated that there were competitive opportunities on the job market for youths and the public through social media. Applying for banks' internships or jobs allows users or applicants to gain exposure to work experiences in the field, obtain probable recruitment, and be enthused by professional and personal knowledge as well as developing employment skills. This was referred to as the 'Recruiting vs Inspired' perspective.

In Category 4 (Awareness Campaigns), banks could reach the target audience through social media and communicate specific advice such as cancer awareness messages, which were tailored to women for better care, deeper knowledge, and empowerment for women regarding breast cancer detection and treatment. Based on knowledge and understanding, these social media campaigns aimed to raise public awareness, interest and behaviour. Due to this, it was referred to as the 'Knowledgeable vs Concerned' perspective.

Most of the created content in Category 5 (Replies and explanations) was informative and useful to viewers because they saw the large number of responses from banks as positive. Banks' online communications here addressed both customers' questions about products or services and complaints about poor service or disruptions. The banks' responses through social media showed a striking commitment to customer satisfaction. Users were turning to banks' social media pages for customer service and to obtain answers to their questions. This perspective was 'Devoted vs Appeased'.

In Category 6 (Greetings and Wishes), banks shared different religious, social, and cultural greetings with customers; these were posted daily on banks' social media pages to establish and maintain personal and emotional relationships. In fact, banks' social media pages evoked reactions, motivated viewers and recognised their values and presence. In this regard, banks' greetings and wishes posts appeared central to users' self-esteem and, more importantly, provided users with a sense of charm and made them feel respected. This perspective was entitled 'Considerate vs Valued'.

\subsubsection{Third: Functional Interpretations}

\subsubsection{Articulated Utterances from Users to Banks}

With reference to users' thematic purposes reflected in the banks' social media pages, each category proposed a different functional area. As described in Figure (2), three broad functional areas were identified: customer care-based issues for Categories 1 and 2, contribution-based issues for Categories 3 and 4, and judgement- and platform-based issues for Categories 5 and 6 .

These areas are incredibly important as, together, they disclose strategic and operational magnitude.

Both Category 1 (Complaints) and Category 2 (Request for Information and Clarification) typically entail customer care affairs. However, the first exposed 
users' resentment, which needed to be addressed. This came under the 'Revelatory Aspect' function, while the second sought detail about banks' product and service issues and other opportunities; this was related to the 'Inquiring Aspect'. These functional areas emphasised the effective roles of social media in presenting and raising customer service issues, which can work faster than traditional onsite channels.

The third and fourth functional areas for Category 3 (Ideas and Suggestions), which was placed under the 'Improving Aspect' and Category 4 (Admiration and Congratulations) functioned under the 'Complimentary Aspect'; both areas were contributory. Through social media, the former category gave views on how to improve performance, while the latter offered positive feedback with esteem and appreciation. Users interactively reacted to the stimulating information and events that banks posted on digital social media and this prompted participation.

Categories 5 (Criticism and Dissatisfaction) and 6 (Irrelevant and Other Contents) were related to the 'Reformatory Aspect' and the 'Social Aspect', respectively. The functional area of Category 5 illustrates the differences in users' attitudes towards banks' services and activities though their expressions of anger and desire for better treatment and improved quality services. However, it was interesting that Category 6 that contained proposals for internal communications between female users using banks' social media pages. This probably symbolised a vital social gathering opportunity for women users in the region.

\subsubsection{The Articulated Utterances from Banks to Users}

As noted in Figure (3), the content shared by banks for users was divided into two large groups. The first group belonged to 'Mercantile or Profit-Orientated Areas', which embraced Categories 1 (Promotions and Advertisements), 2 (News and Notification), and 3 (Youth Training and Job Opportunities), which all came under purposes of commercial aspects. The second group was concerned with 'Proximity or Closeness-Related Areas' and was composed of Categories 4 (Awareness Campaigns), 5 (Replies and Explanations), and 6 (Greetings and Wishes), which emerged within the relational facets.

The categories that fell within the first group were directly or indirectly connected with banks' business or other undertakings intended mainly for profit. On the contrary, categories of the second group focused on the relationships that involved reciprocal communication, knowledge, attraction, dialogue, and collaboration.

\section{CONCLUSION AND RECOMMENDATION}

\subsection{Conclusion}

The growing advancement of digital technologies and the emergence of varying social network trends urges banks to consider the way their customers utilise the internet and the content they produce on social media, and, hence, plan accordingly.

As previously stated, this study aimed to understand the type of content shared between users and banks on banks' social media pages. This paper analysed the 
shared content from three comprehensive dimensions and emphasised crucial gender and economic development issues. The study also focused on human and empowerment elements that emerged from the interactions between users and banks.

The study exposed that the interactions between users and banks on social media was effective in bringing several levels of empowerment in various forms for both users and banks. More women were found to feel excitement and participate in social activity than communicating with banks for details about financial products or services, unlike men, who were more interested in knowing information about banking services. Both men and women users addressed banks and shared the right to more beneficial financial services and products and improved customer services; however, women lagged behind because a higher number of women remained financially excluded.

To summarise, the in-depth classification achieved through the examination of content suggests that the use of social media in banks is beneficial for users and banks and could engender users, as well as enhance financial inclusion, despite the gender gap that persists in Arab countries.

\subsection{Recommendation}

Banks' shareholders, financial intuition management, and customer service departments in the banking sector need to ensure that the continual use of social media is in line with banks' missions and social responsibility so that a real difference for women can be achieved. This still seems relatively low in terms of financial inclusion in Arab regions and countries.

Central Banks' monitors and regulators may wish to develop policies and regulations that help banks to continue to utilise social media and simultaneously protect users' privacy and rights to freely use these digital platforms to achieve their goals and reach empowerment.

Future studies might involve a comparative analysis of social media usage among several regions and/or various industries. Another interesting area might be to focus on studying social media users, their personal social media sites, and so on to explore the influence or relationship between aspects of users' demographic data and the use of social networks.

\subsection{Limitations}

Amongst the limitations of this study were confined sampling and social media type. A larger number of users and banks with more than one social media network would probably have provided more fertile content for significant comparative analysis and further implicational details and dimensions. Another limitation was the unequal representation of participants by gender; the ratio of female users was lower than that of male users in most of the five banks' social media pages. So, future research may adopt a quota sampling technique in relation to banks and countries to overcome this gender- imbalanced deficiency.

Other limitations that may influence findings include the issues of timing and region. This study took place during the period January to May 2019 and, 
unintentionally, embraced considerable religious, cultural, and social events. For instance, Ramadan, the holy month for Muslims, encountered the month of May while March was pleasantly described by some participants as 'the month of women' as it included International Women and Mother's Days, in addition to the month of April, which contained the Arab Financial Inclusion event. Prospective studies should pay attention to the effect of time on when events happen within a region.

\section{REFERENCES}

Afolabi, I. T., Ezenwoke, A. A., \& Ayo, C. K. (2017). Competitive Analysis of Social Media Data in The Banking Industry. International Journal of Internet Marketing and Advertising, 11(3), 183. https://doi.org/10.1504/ijima.2017.10006719

Al-Kandari, A. A., Gaither, T. K., Alfahad, M. M., Dashti, A. A., \& Alsaber, A. R. (2019). An Arab Perspective on Social Media: How Banks in Kuwait use Instagram for Public Relations. Public Relations Review, (July 2018), 0-1. https:// doi.org/10.1016/j.pubrev.2019.04.007

Allagui, I. \& Breslow, H. (2016). Social Media for Public Relations: Lessons from Four Effective Cases. Public Relations Review, 42(1), 20-30. https://doi. org/10.1016/j.pubrev.2015.12.001

Alrwashdeh, M., Emeagwali, O. L., \& Aljuhmani, H. Y. (2019). The Effect of Electronic Word of Mouth Communication on Purchase Intention and Brand Image: An Applicant Smartphone Brands in North Cyprus. Management Science Letters, 9, 505-518. https://doi.org/10.5267/j.msl.2019.1.011

American Bankers Association. (2017). The State of Social Media in Banking, Results of an American Bankers Association. 1-22. Retrieved from https://www.aba.com/ Products/Endorsed/Documents/ABASocialMedia_Report.pdf

Arab Bank Jordan. (2019). [ Facebook Pages, Posts and Communications]. Retrieved from https://www.facebook.com/ArabBank/

Arab Monetary Fund. (2018). Arab Financial Inclusion Day [Press Release]. Retrieved from https://www.centralbank.ae/sites/default/files/2018-10/ PressRealse26042018_English.pdf

Bank of Palestine. (2019). [Facebook Pages, Posts and Communications]. Retrieved from https://www.facebook.com/BankofPalestine

Batista, D. C., Silva, T., Stabile, M., Páez, P. C., \& Kearney, M. (2017). Insights from Social Media on Gender in Latin America. Inter-American Development Bank, 1-72. Retrieved from http://dx.doi.org/10.18235/0000801

Cattaneo, L. B. \& Chapman, A. R. (2010). The Process of Empowerment: A Model for Use in Research and Practice. American Psychologist, 65(7), 646-659. https:// doi.org/10.1037/a0018854

Commercial International Bank Egypt. (2019). [Facebook Pages, Posts and Communications]. Retrieved from https://www.facebook.com/CIBEgypt

First Abu Dhabi Bank United Arab Emirates. (2019). [Facebook Pages, Posts and Communications]. Retrieved from https://www.facebook.com/FAB/

Gandolfo, A. (2019). Content Shared between Banks and Users on The Social Ecosystem: An Inductive Exploratory Inquiry. In Electronic Commerce Research. https://doi.org/10.1007/s10660-019-09340-z 
Global Finance Magazine. (2018). [World's Best Bank Awards 2018: The Middle East]. Retrieved from https://www.gfmag.com/magazine/may-2018/worlds-bestbanks-middle-east-2018

Hesse-Biber, S. N. (2017). The Practice of Qualitative Research (Third Edit), London, SAGE Publications, Inc.

Khan, F. R., Al-balushi, H. Y., Algaithi, A. D., \& Al-shihi, A. A. (2017). Impact of Social Media on Customers Satisfaction: Bank Muscat - A Case Study. Ahead International Journal of Recent Research Review, 1(11), 154-164. Retrieved from https://ssrn.com/abstract=2979972

Kaletski, E. \& Randolph, S. (2018). Economic Rights Working Paper Series Securing Economic and Social Rights: Obstacle or Handmaiden to Growth? University of Connecticut, Working Paper 26, Human Rights Institute. Retrieved from https://media.economics.uconn.edu/working/HRI26.pdf

Kaosiri, Y. N., Fiol, L. J. C., Tena, M. Á. M., Artola, R. M. R., \& García, J. S. (2019). User-Generated Content Sources in Social Media: A New Approach to Explore Tourist Satisfaction. Journal of Travel Research, 58(2), 253-265. https://doi. org/10.1177/0047287517746014

Kietzmann, J. H., Hermkens, K., McCarthy, I. P., \& Silvestre, B. S. (2011). Social Media? Get Serious! Understanding The Functional Building Blocks of Social Media. Business Horizons, 54(3), 241-251. https://doi.org/10.1016/j. bushor.2011.01.005

Kwauk, C., \& Braga, A. (2017). Translating Competencies to Empowered Action, Center for Universal Education, The Brookings Institution. (November). Retrieved from https://www.brookings.edu/wp-content/uploads/2017/11/ translating-competencies-empowered-action.pdf

Mahboub, R. M. (2018). The Impact of Social Media Usage on Performance of the Banking Sector in Middle East and North Africa Countries. International Journal of Economics and Business Administration, VI (3), 3-20. Retrieved from https://www.ijeba.com/dmdocuments/2018/2018_VI_3_01.pdf

Mitic, M. \& Kapoulas, A. (2012). Understanding The Role of Social Media in Bank Marketing. Marketing Intelligence \& Planning, 30(7), 668-686. https://doi. org/10.1108/02634501211273797

Mucan, B. \& Özeltürkay, E. Y. (2014). Social Media Creates Competitive Advantages: How Turkish Banks Use This Power? A Content Analysis of Turkish Banks through their Webpages. Procedia - Social and Behavioral Sciences, 148, 137-145. https://doi.org/10.1016/j.sbspro.2014.07.027

Naeem, M. (2019). Understanding The Role of Social Networking Platforms in Addressing The Challenges of Islamic Banks. Journal of Management Development, 38(8), 664-680. https://doi.org/10.1108/jmd-04-2019-0107

National Bank of Kuwait. (2019). [ Facebook Pages, Posts and Communications]. Retrieved from https://www.facebook.com/NBKGroup/

Ozili, P. K. (2018). Impact of Digital Finance on Financial Inclusion and Stability. Borsa Istanbul Review, 18(4), 329-340. https://doi.org/10.1016/j.bir.2017.12.003

Parusheva, S. (2017). Social Media Banking Models: A Case Study of A Practical Implementation in Banking Sector. Ikonomicheski Izsledvania, 26(3), 125-141. Retrieved from https://www.researchgate.net/publication/320142155. 
Peeroo, S., Samy, M., \& Jones, B. (2018). Trialogue on Facebook Pages of Grocery Stores: Customer Engagement or Customer Enragement? Journal of Marketing Communications, (June), 1-23. https://doi.org/10.1080/13527266.2018.1482559

Perkins, D. D., \& Zimmerman, M. A. (1995). Empowerment Theory, Research, and Application. American Journal of Community Psychology, 23(5), 569-579. https:// doi.org/10.1007/BF02506982

Rieder, B. (2013). Studying Facebook via Data Extraction. Proceedings of the 5th Annual ACM Web Science Conference on - WebSci '13, 346-355. https://doi. org/10.1145/2464464.2464475

Sandelowski, M. (1995). Focus on Qualitative Method: Sample Size in Qualitative Research. Research in Nursing and Health, 18, 179-183. https://doi.org/10.1002/ nur.4770180211

Sarkar, B. \& Saini, R. K. (2018). Use of Sentiment Analysis for Peer-to-Peer Lending Customer Engagement. Sansmaran Research Journal, 1-11. Retrieved from https://search.proquest.com/docview/2090312002?accountid=17242

Shin, H., Perdue, R. R., \& Pandelaere, M. (2019). Managing Customer Reviews for Value Co-creation: An Empowerment Theory Perspective. Journal of Travel Research, 1-19. https://doi.org/10.1177/0047287519867138

Singh, A., Kumar, K., McDougal, L., Silverman, J. G., Atmavilas, Y., Gupta, R., \& Raj, A. (2019). Does Owning A Bank Account Improve Reproductive and Maternal Health Services Utilization and Behavior in India? Evidence from the National Family Health Survey 2015-16, Elsevier Ltd. SSM - Population Health. https://doi.org/10.1016/j.ssmph.2019.100396

Social Baker Database. (2019). [Free Social Media Statistics, Facebook Pages Stats]. Retrieved from https://www.socialbakers.com/statistics/facebook/pages/total/ egypt/brands/finance/

Sumathi, N. \& Sheela, T. (2017). An Efficient Sentiment Analysis by using Hybrid Naive Bayes and Svm Approach in Banking Institutions. International Journal of Civil Engineering and Technology, 8(12), 373-391. Retrieved from http://www. iaeme.com/IJCIET/issues.asp?JType=IJCIET\&VType=8\&IType=12

Thoumrungroje, A. (2014). The Influence of Social Media Intensity and EWOM on Conspicuous Consumption. Procedia - Social and Behavioral Sciences, 148(November 2012), 7-15. https://doi.org/10.1016/j.sbspro.2014.07.009

Torres, P., Augusto, M., \& Wallace, E. (2018). Improving Consumers' Willingness to Pay using Social Media Activities. Journal of Services Marketing, 32(7), 880896. https://doi.org/10.1108/JSM-07-2017-0257

Vasileiou, K., Barnett, J., Thorpe, S., \& Young, T. (2018). Characterising and Justifying Sample Size Sufficiency in Interview-Based Studies: Systematic Analysis of Qualitative Health Research Over A 15-Year Period. BMC Medical Research Methodology, 18(1). https://doi.org/10.1186/s12874-018-0594-7

Yakobi, K. \& Ngcamu, B. S. (2016). An Exploratory Study on The Impact of Social Media of Selected Commercial Banks in the Eastern Cape Province, South Africa. Banks and Bank Systems, 11(2), 95-102. https://doi.org/10.21511/ bbs.11(2).2016.09

Zimm, C. (2019). Methodological Issues in Measuring International Inequality in Technology Ownership and Infrastructure Service use. Development Studies Research, 6(1), 92-105. https://doi.org/10.1080/21665095.2019.1605533 
Zimmerman M.A. (2000). Empowerment Theory. In: Rappaport J., Seidman E. (eds) Handbook of Community Psychology. Springer, Boston, MA. Retrieved from https://link.springer.com/chapter/10.1007/978-1-4615-4193-6_2 